\title{
SUSTENTABILIDADE APLICADA À MODA COMO POSSÍVEL FATOR DE INFLUÊNCIA NA DECISÃO DE COMPRA
}

\section{SUSTAINABILITY APPLIED TO FASHION LIKE A POSSIBLE FACTOR OF INFLUENCE IN THE PURCHASE DECISION}

\author{
Luiza Lima Frazão ${ }^{1}$, Gylnara Kylma Feitosa Carvalhêdo Almeida ${ }^{2}$, \\ Karoline de Lourdes Monteiro Guimarães ${ }^{3}$, Pablo Diego Araújo Neves ${ }^{4}$.
}

\begin{abstract}
RESUMO: No setor da moda, muitos aspectos podem levar os consumidores à compra, desde o aspecto funcional de vestir-se, ou mesmo pelos aspectos estético, econômico, simbólico ou, mais recentemente, sustentável. Sobre o assunto, esta pesquisa tem como objetivo verificar se o fator sustentável aplicado à moda poderia influenciar no momento da decisão de compra de consumidores da cidade de São Luís, localizada no estado do Maranhão. Para isso, foi realizada uma pesquisa de campo com questionário junto a uma amostragem de 30 pessoas em uma Instituição de Ensino Superior e em um shopping da cidade. Como resultados, foram ouvidos homens e mulheres entre 30 a 35 anos, e observou-se que para $80 \%$ da amostra, a característica sustentável poderia influenciar no momento da escolha da peça de vestuário, mas desde que a peça não possua diferença no preço.
\end{abstract}

PALAVRAS - CHAVE: Sustentabilidade. Moda. Consumo sustentável.

\begin{abstract}
In the fashion sector, many aspects may lead consumers to purchase, since the functional aspect to just get dressed, or even the aesthetic aspects, economic, symbolic or, more recently, sustainable. About the subject, the objective of this research aims at verifying that the sustainable factor applied to the fashion could influence at the time the consumer's purchase decision in the city of São Luís, localized in the State of Maranhão. To it, a field survey questionnaire was conducted with a questionary among 30 people in a higher education institution and in a city mall. As a result, men and women were heard between 30 to 35 years old, and it was observed that for $80 \%$ of the sample, the sustainable feature could influence in the moment of dress purchase, but whereas the piece had no difference in price.
\end{abstract}

KEYWORDS: Sustainability. Fashion. Sustainable Consumption.

\footnotetext{
${ }^{1}$ Bacharel em Design. Egressa da Universidade Ceuma. E-mail: luizalima_7@hotmail.com

${ }^{2}$ Mestranda em Meio Ambiente pela Universidade Ceuma. Professora da Universidade Ceuma. E-mail: gylnara@ gmail.com

${ }^{3}$ Mestre em Design pela Universidade Federal do Maranhão/UFMA. Professora da Universidade Ceuma. E-mail: kgguimaraes@hotmail.com

${ }^{4}$ Mestre em Design pela Universidade Federal do Maranhão/UFMA. Professor da Universidade Ceuma. E-mail: pdaneves@ gmail.com
} 


\section{INTRODUÇÃO}

O descompasso entre a necessidade de um sistema produtivo que atenda as demandas e a exploração dos recursos naturais sem planejamento prejudica o meio ambiente e seu equilíbrio natural (OLIVEIRA, 2015), refletindo suas consequências nocivas ao homem, que precisa do meio para suas necessidades mais básicas. Segundo Buarque (2002, p. 30), o processo de industrialização, com seu excesso de produção e exploração dos recursos de modo não responsável, “(...) tende a degradar e destruir o meio ambiente e os recursos, levando no futuro a um estrangulamento de possibilidades de desenvolvimento e a um comprometimento da qualidade de vida da população".

Observa-se que existe, atualmente, uma preocupação com as questões relacionadas ao meio ambiente. Desde 1970, com o surgimento de movimentos com ênfase ambiental, o pensamento consciente de preocupação com o aspecto ambiental foi ganhando seu espaço. Hoje, a sustentabilidade aplicada à moda apresenta preocupação com o meio ambiente, preocupando-se com um futuro com melhor qualidade de vida. O uso de modo abundante dos recursos naturais, como o consumo exagerado por parte da população, tem gerado a degradação ambiental, causada pela grande quantidade de resíduos consumidos em sua produção, sendo esses alguns dos sinais inerentes aos danos causados ao meio ambiente.

O termo 'sustentável' é, atualmente, considerado uma estratégia de marketing na venda de produtos a pessoas que acreditam em um mundo sustentável. Com base neste fundamento, algumas empresas buscam agregar valores aos seus produtos intitulando-os como sustentáveis e, diante desta ideia, surge a seguinte questão: O fator sustentável aplicado à moda pode influenciar no momento da decisão de compra? Como forma de solucionar esta indagação, esta pesquisa foi desenvolvida com base na literatura disponível, seguida da aplicação de questionário composto por perguntas abertas e fechadas, com uma amostragem de trinta (30) consumidores de ambos os sexos, com faixa etária de 30 a 35 anos, na cidade de São Luís, no estado do Maranhão.

\section{A SUSTENTABILIDADE E A MODA}

A sustentabilidade, para Brown (2009), pode ser definida como a área ambiental que busca promover o desenvolvimento econômico, visando minimizar os impactos ambientais para garantir recursos naturais às gerações atuais e futuras. Ela não defende o fim do consumo ou de processos produtivos, mas que ocorram de modo adequado, garantindo recursos, porém com o mínimo de impacto para o meio ambiente e gerações futuras. 
Boyd (2001), ao falar que a sustentabilidade é tida como um tripé, ressalta que envolve respeito ao meio ambiente, viabilidade econômica e responsabilidade social. Neste último ponto, Dias (2010, p. 153) explica que "a responsabilidade social em questões ambientais se tem traduzido em adoção de práticas que extrapolam os deveres básicos tanto do cidadão quanto das organizações". Ou seja, é pensar e fazer além, para o agora e para o futuro, é pensar em estratégias de desenvolvimento de modo sustentável.

O uso de modo abundante dos recursos naturais, a grande quantidade de resíduos dos processos produtivos e o descarte inadequado oriundo do consumo exagerado geram a degradação ambiental. De acordo com Kumar (apud Salcedo, 2014), o século XX foi o século da ciência e da tecnologia. A época do crescimento econômico, o século do petróleo. No século XXI, estamos experimentando as consequências dos excessos do século anterior.

Neste cenário, a moda apresenta fatores que geram poluição e degradação ambiental (ARAÚJO, 2015), pois ela, unida à Publicidade, incentiva o rápido descarte. A intensa produção da moda vem gerando impactos ao meio ambiente, fazendo-se necessário reflexões e novos hábitos. Isto enseja a importância de novos hábitos aplicados à moda. A moda tem o poder de representar a personalidade de cada pessoa, como uma maneira de individualização. Está diretamente relacionada a costumes, crenças, cultura e pode conter vários aspectos como fatores que possam influenciar. Segundo Palomino (2003, p. 14), "você enxergará melhor a moda se conseguir visualizar uma evolução.” A partir das roupas, do modo que o indivíduo se apresenta, pode-se obter a reflexão pelo vestuário das sociedades, da época que se trata. Um bom exemplo que pode ser observado são os conhecidos filmes, ou novelas de época, onde o tempo é caracterizado pelo vestuário dos personagens. A moda vai além de blusas, calças, camisetas e vestidos, mas inclui biquínis, peças intimas e acessórios como bolsas, sapatos, óculos, bijuterias etc.

Neste contexto, apresenta-se a Moda Sustentável. Salcedo (2014, p. 32) refere que "a moda sustentável surgiu para englobar todas aquelas peças de roupa e outros produtos de moda feitos através de métodos menos prejudiciais ao meio ambiente, com possibilidade de reduzir o impacto ambiental”. Segundo Ger (1999), o consumo sustentável possui foco nas políticas ambientais em relação ao controle dos processos de produção, considerando assim que o comportamento social consumista é o real desencadeador da crise ambiental. Para Oliveira e Cândido (2010), o consumo sustentável se insere na sociedade em meio a aspectos regidos pelos atuais padrões e níveis de consumo da sociedade capitalista moderna que visa proteção ambiental, interesses sociais, culturais, econômicos e tecnológicos, construindo pilares para o projeto de uma futura sociedade sustentável sob ética e responsabilidade social e ambiental. 


\section{O COMPORTAMENTO DO CONSUMIDOR E O PROCESSO DE MOTIVAÇÃO DE COMPRA}

De acordo com Kotler (2000), o comportamento de compra sofre influências de fatores sociais, pessoais, culturais e psicológicos. Junto a esses fatores são considerados aspectos como classe social, valores, estilo de vida, características demográficas, motivações, preferências, grupos de referências, entre outros. Neste sentido, o processo de motivação de compra está diretamente ligado às necessidades que o consumidor possa ter e ao seu comportamento diante do consumo. De acordo com Solomon (2002), os motivos possuem direção e força. São orientados para uma meta, em que objetivos específicos são desejados buscando satisfazer uma necessidade A meta pode ser alcançada por uma série de caminhos, e o objetivo é convencer os consumidores de que a alternativa que eles oferecem seja a melhor oportunidade para chegar à meta.

O processo de decisão de compra do consumidor ocorre a partir das etapas definidas por Pinheiro et al. (2004), das quais primeiro há o reconhecimento da necessidade pelo consumidor, depois a busca de informação para mais conhecimento sobre o produto ou serviço, a avaliação das alternativas de produto, a decisão de compra e o comportamento pós-compra. Dessa forma, qual a necessidade do consumidor? Contribuir para o meio ambiente? Neste ponto, a propaganda pode influenciar no reconhecimento da necessidade de compra, e seu novo segmento, o marketing ecológico. A partir desse segmento, muitas empresas buscam atrelar a característica sustentável à gestão da empresa, visando atribuir valores sustentáveis à empresa e aos seus produtos.

\section{MARKETING ECOLÓGICO}

Marketing consiste no processo social no qual "pessoas e grupos de pessoas obtêm aquilo de que necessitam e o que desejam com a criação, oferta e livre negociação, com outros, de produtos e serviços e valor" (KOTLER, 1988, p. 29). Donaire (1995) completa ao afirmar que corresponde ao conjunto de diversas atividades que tem por intuito viabilizar a chegada do produto pronto ao consumidor final. Ou seja, corresponde a um processo no qual existe um produto e um indivíduo, que deverão se encontrar durante a aquisição do produto pelo consumidor. Neste ponto, a viabilização para que isto ocorra depende de muitos fatores que podem exercer influência, tornando o processo de compra mais eficiente ou não. Dentre estes fatores, o aspecto ambiental tem ganhado espaço e importância em estratégias de marketing, visto que desde a década de 70 se discute o assunto e, mais recentemente, há uma crescente conscientização dos consumidores ou mesmo uma 
maior disponibilidade de informações acerca das problemáticas dos processos produtivos e sua relação com impactos ambientais.

Neste sentido, Dias (2010) considera que está se consolidando um novo tipo de consumidor, chamado popularmente de 'consumidor verde'. Trata-se do comprador que se preocupa com o meio ambiente e busca demonstrar isto em seu estilo de vida, principalmente em suas escolhas ao realizar uma compra. Neste ponto, a preocupação ambiental deixa de ser um fato social da contemporaneidade e passa a ser considerada como um novo fenômeno de marketing.

\section{METODOLOGIA}

Este trabalho consiste em uma pesquisa descritiva com abordagem qualitativa. Seu desenvolvimento se deu a partir do levantamento de referencial teórico sobre moda sustentável. Em um segundo momento, foram realizados o planeamento e o desenvolvimento de pesquisa de campo para coleta de dados provenientes da aplicação de um questionário com consumidores. O questionário foi estruturado com doze (12) perguntas, das quais onze (11) foram fechadas e somente uma (1) aberta, aplicadas de modo presencial durante duas (2) semanas, em uma Instituição de Ensino Superior (IES) e em um shopping na cidade de São Luís - MA. A amostragem estabelecida foi de trinta (30) pessoas de ambos os sexos, escolhidas de modo aleatório; contudo, como critério de delimitação, foram escolhidas pessoas entre 30 a 35 anos, uma vez que esta faixa etária costuma estar inserida no mercado de trabalho, expressando, possivelmente, uma fonte de renda e, consequente poder de compra. Por fim, a tabulação dos dados e desenvolvimento dos gráficos foram realizados com o uso dos softwares Word e Excel, ambos na versão 2016.

\section{ANÁLISE DOS RESULTADOS E DISCUSSÕES}

Para uma melhor visualização e entendimento dos dados, os resultados foram divididos em três partes, das quais houve a caracterização da amostragem para reconhecimento do público trabalhado, caracterização do interesse em moda e, mais especificamente, da moda sustentável, além da simulação do momento de compra, no qual observou-se preferência do consumidor por produtos entre os considerados sustentáveis e os não sustentáveis. Após a coleta dos dados, provenientes da aplicação dos questionários, realizou-se a tabulação e verificou-se que os consumidores entrevistados com faixa etária de 30 a 35 anos corresponderam a $57 \%$ do gênero feminino e $43 \%$ do gênero masculino, todos residentes na capital maranhense.

Quanto à remuneração, 50\% disseram possuir renda familiar mensal acima de 5 salários mínimos e $20 \%$ disseram possuir renda até quatro salários mínimos, como mostra o Gráfico 1. 


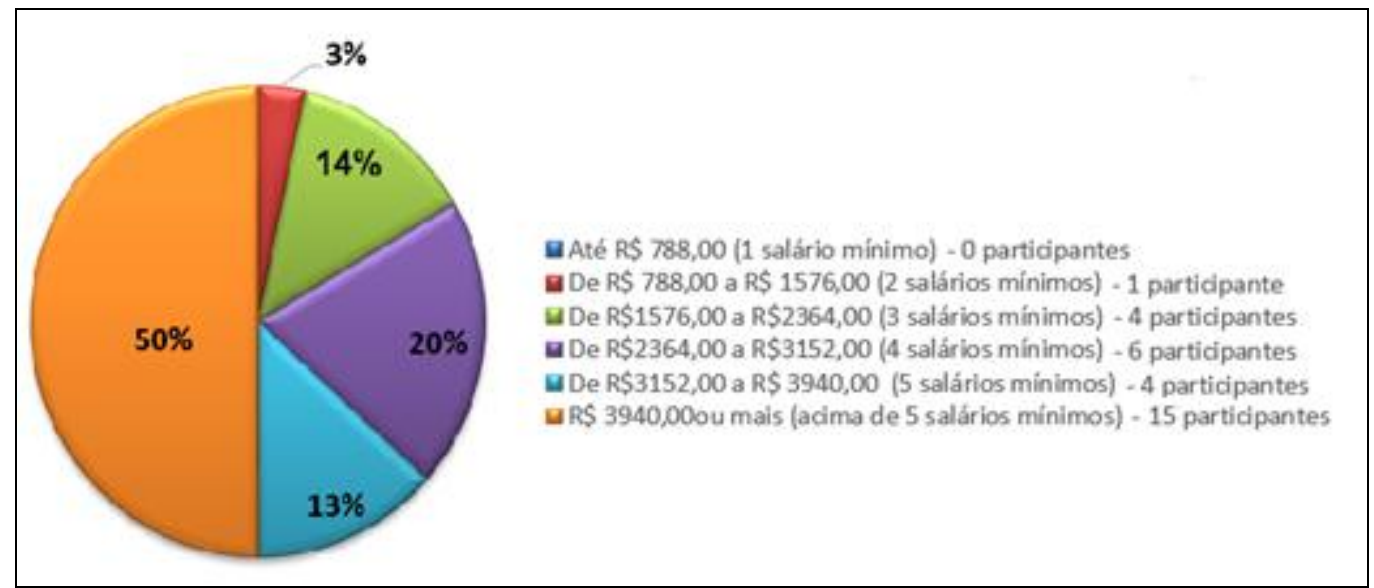

Gráfico 1: Renda mensal da amostragem.

Com essa porcentagem maior, acredita-se que os consumidores participantes teriam maior possibilidade de consumir uma grande quantidade de produtos e a preços menos populares, tornando-se o preço elevado como algo que possivelmente não influencie no momento da decisão de compra.

Com relação à frequência de consumo, questionou-se com que frequência os consumidores compravam roupas, como mostra o Gráfico 2. Os resultados obtidos mostraram que a grande maioria da amostragem tem o hábito de consumo somente quando se faz necessário, o que representou $63 \%$ dos participantes. A opção "1 vez por mês" teve o segundo maior número na contagem, totalizando $27 \%$ da amostragem, o que corresponde a oito sujeitos que possuem hábito de consumir roupas com esta frequência.

\section{Frequência de compra}

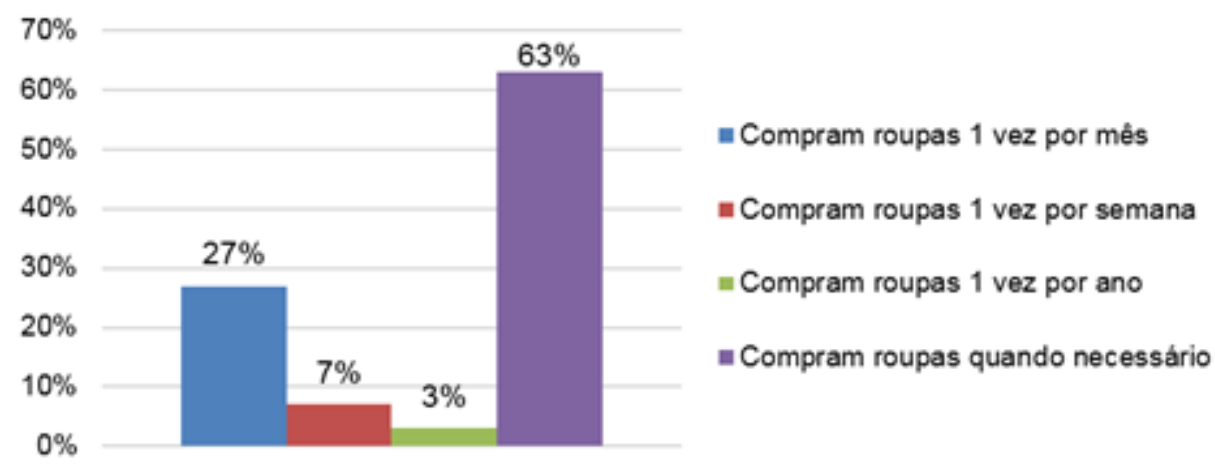

Gráfico 2: Resposta da amostragem com base no questionário. 
Apenas dois consumidores apresentaram maior assiduidade em relação ao consumo de vestuário, com a opção "1 vez por semana", tendo como representação 7\%. Por fim, somente um sujeito disse não ter hábitos frequentes, escolhendo a opção "1 vez por ano", correspondendo à porcentagem de $3 \%$ do gráfico.

Diante desses primeiros resultados, percebeu-se que a maior porcentagem de renda familiar mensal - 50\% disse possuir renda acima de cinco salários mínimos - demonstra que a amostragem realmente pode comprar quando desejar, o que sugere uma possível discordância com os $63 \%$ da pergunta anterior, pois a maioria prefere realizar a compra somente quando necessário.

\section{Caracterização do interesse em moda e moda sustentável}

Nesta etapa, buscou-se avaliar se os consumidores teriam interesse por moda, se buscavam informações e/ou acompanhavam as tendências, além de observar se havia o entendimento e a influência do termo "sustentável”. Os resultados podem ser observados por meio do Gráfico 3:

Gráfico 3: Respostas da amostragem com base no questionário.

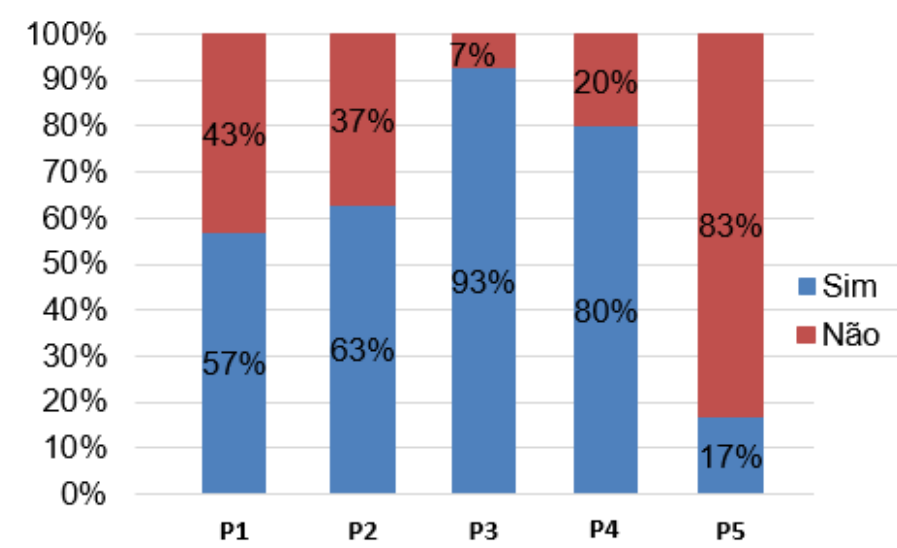

P1 - Você se interessa por moda busca informações, acompanha e observa as tendências?

P2 - Você sabe o que é moda sustentável?

P3 - Você compraria uma peça com conceito sustentável?

P4 - A característica 'sustentável' pode influenciar na sua decisão no momento da escolha de peças de vestuário?

P5 - Antes de adquirir uma peça de vestuário você tem a preocupação em constatar como foi feita sua produção e se ele afeta o meio ambiente?

Perguntou-se inicialmente: "Você se interessa por moda, busca informações, acompanha e observa as tendências?" Neste ponto, notou-se que há um considerável equilíbrio de interesse pelos consumidores, pois $57 \%$ dos participantes disseram 'sim' e 43\% disseram 'não'. Dessa forma, verificou-se que a maior parte dos entrevistados (dezessete) possuíam este interesse por moda. Isto nos permite inferir que pode haver um aspecto de motivação para o consumo de peças de vestuário, já que a disposição para acompanhar a moda e suas tendências se mostra maior. 
Assumindo-se que o conhecimento ou a falta deste é um fator relevante no momento da decisão de compra, buscou-se verificar se os consumidores sabiam e entendiam acerca da moda sustentável. Acreditava-se que grande parte possuía este conhecimento, uma vez que este é um assunto evidenciado pela mídia em informativos do segmento, e as respostas confirmaram a hipótese, pois $63 \%$ da amostragem disse saber o que é a moda sustentável.

Diante da presença de conhecimento pela maioria dos participantes, acreditava-se que grande parte compraria uma peça de vestuário com conceito sustentável e, para além das expectativas, 93\% da amostragem respondeu "sim". Isto demonstra que há uma receptividade da característica sustentável aplicada à peça de vestuário pelos consumidores.

Realizando um resgate das ideias de Dias (2010), que acredita que o aumento da consciência ambiental no mundo está sendo consolidando com o 'consumidor verde', este cenário expressa uma possível existência de consciência diante do tema ou mesmo um interesse inferido frente a tantas informações que são disponibilizadas pela mídia. Assim, a porcentagem de 93\% pode ser vista como de "consumidores verdes" em desenvolvimento.

Dentre os que afirmaram que comprariam uma peça de vestuário com conceito sustentável, $63 \%$ relataram possuir conhecimento sobre moda sustentável. Com base nesse universo de 30 entrevistados, $70 \%$ da amostra afirmaram já possuir hábitos sustentáveis

Contudo, os resultados mostram que, apesar de grande parte afirmar a relevância do conceito sustentável, a maioria dos consumidores não se preocupa com os impactos dos processos produtivos dos produtos que consome. $80 \%$ afirmaram que a característica "sustentável" aplicada à moda poderia influenciar no momento da decisão de compra. Contudo, este suposto interesse não foi observado nas atitudes dos mesmos consumidores, uma vez que afirmaram logo em seguida que apenas $17 \%$ busca constatar se o processo produtivo da peça de vestuário a ser comprada afeta o meio ambiente. Ora, isto demonstra uma ausência de concordância entre aquilo que os consumidores defendem e suas atitudes.

\section{Preferência de produtos: sustentáveis $x$ não sustentáveis}

Diante da falta de concordância entre aquilo que os consumidores defendem e sua prática no momento da compra, foi simulada uma situação de aquisição de produtos, disponibilizando uma informação generalista acerca do processo produtivo. Esta simulação estava contida no questionário; a amostragem foi exposta a imagens de peças de roupas e um fragmento de texto, escolhendo uma das peças para “comprar". Em um total de duas (2) situações, as questões a seguir tiveram o intuito de verificar se o fator sustentável poderia influenciar na decisão. As perguntas foram estruturadas da seguinte forma: 1 - Peça industrial com valor mais elevado (Figura 1); 2 Peça sustentável de maior preço (Figura 2). 
Nas Figuras 1 e 2, buscou-se analisar a escolha dos participantes frente à relação estabelecida entre os produtos e diferentes valores. $\mathrm{Na}$ primeira, foram utilizadas camisetas semelhantes, porém com valores diferentes.

Se tivesse que escolher entre estes produtos para comprar, qual escolheria?

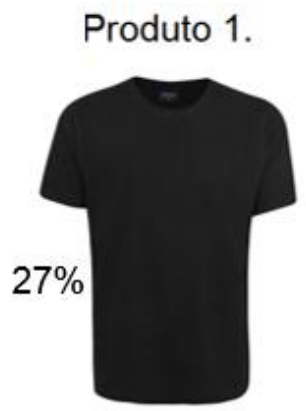

$\mathrm{R} \$ 70,00$.

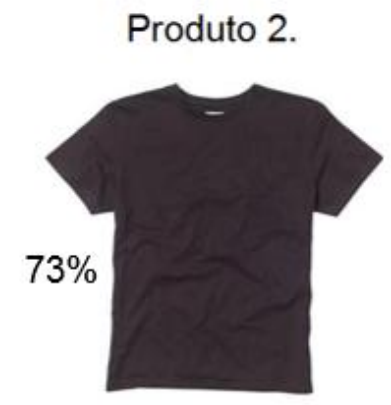

$\mathrm{R} \$ 50,00$.

$100 \%$ algodão orgânico

Figura 1: Preferência da amostragem quanto aos produtos de valores diferentes.

O produto com conceito sustentável foi colocado com menor preço. Descartando o preço como possível fator de influência, a camiseta de algodão 100\% orgânico (produto 2) com menor preço obteve maior preferência ( $73 \%$ da amostragem). Neste contexto, questiona-se se os resultados mostraram que a preferência se deu devido ao conceito sustentável ou ao preço?

Frente à questão acima, tem-se a Figura 2, na qual foram utilizados vestidos cujo conceito sustentável agora passou a apresentar um maior valor. Os resultados mostraram que $63 \%$ optou pela peça de menor custo, com fabricação industrial, demonstrando que, neste caso, o fator sustentável foi desconsiderado diante do fator preço, este apresentando-se como o fator na decisão de compra que foi considerado, assim como ocorreu na figura anterior.

\section{Se tivesse que escolher entre estes produtos para comprar, qual escolheria?}

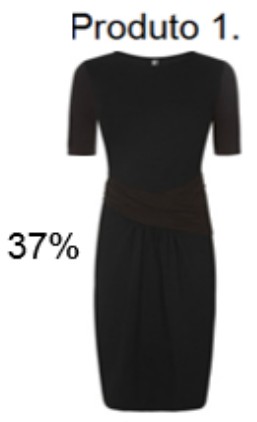

$\mathrm{R} \$ 70,00$.

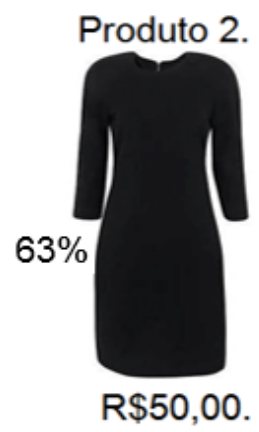

95\% de algodão orgânico,

$5 \%$ elastano. 
Figura 2: Preferência da amostragem quanto ao processo de fabricação dos produtos.

Mesmo sem conhecimento do termo "sustentabilidade", pôde-se verificar que a sociedade apresenta-o como uma característica positiva, porém o 'discurso' não acompanhou a prática da amostragem desta pesquisa. Por isso, a escolha do consumidor se traduz para o 'ecologicamente correto', porém desde que a peça não tenha diferença no valor. $\mathrm{O}$ aspecto sustentável das peças não predominou como decisivo na escolha, pois a amostragem escolheu produtos com menor preço nas duas situações.

\section{CONCLUSÃO}

A criação de hábitos sustentáveis tem sido uma necessidade inerente à humanidade desde que se passou a perceber que os recursos naturais e as matérias-primas serão esgotáveis. Assim, a preservação ambiental e a criação de novas alternativas, que impulsionassem o desenvolvimento econômico sem causar impacto ao meio ambiente, têm sido uma possibilidade buscada por diversos setores da indústria, como o setor têxtil. Observa-se que empresas do setor buscam agregar valor aos seus produtos, intitulando-os como sustentáveis, conquistando consumidores chamados de “consumidores verdes". A partir de tais informações, buscou-se verificar se o fator sustentável aplicado à moda poderia influenciar de alguma forma na decisão de compra nos consumidores da cidade de São Luís. Apesar de 93\% da amostragem ter demonstrado receptividade ao responder que comprariam produtos com a característica sustentável, e $80 \%$ da amostra relatar que a característica sustentável poderia influenciar no momento da escolha da peça de vestuário, os participantes preferiram peças com preços mais acessíveis nas duas simulações de compra. 


\section{REFERÊNCIAS}

ARAÚJO, M. A. Moda ecológica ou ecologia para a moda. Disponível em: <http://www.idhea.com.br/pdf/Moda\%20Ecol\%C3\%B3gica\%20ou\%20Ecologia\%20para\%20a\%20 Moda.pdf>. Acesso em: 10 set. 2015.

BOYD, C. Sustainability is good business. OECD Observer, n. 228, p. 35, 2001.

BROWN, L. R. Plano, B. 4.0: mobilização para salvar a civilização. São Paulo: New Content, 2009.

BUARQUE, S. C. Construindo o desenvolvimento local sustentável: metodologia de planejamento. São Paulo: Garamond, 2002.

DIAS, R. Gestão ambiental: responsabilidade social e sustentabilidade. São Paulo: Atlas, 2010. DONAIRE, D. Gestão ambiental na empresa. São Paulo: Atlas, 1995.

GER, G. Consumption and Environmental Sustainability Across Cultures. Advances in Consumer Research, v. 26, p. 271, 1999.

KOTLER, P; ARMSTRONG, Gary. Fundamentos de mercadotecnia. São Paulo: Prentice Hall, 1988.

KOTLER, P. Marketing para o século XXI: como criar, conquistar e dominar mercados. São Paulo: Futura, 2000.

OLIVEIRA, D. M. Capitalismo e meio ambiente: a ideologia capitalista em declínio e os desafios do planejamento ecológico. Olhares Plurais, v. 1, n. 12, p. 34-47, 2015.

OLIVEIRA, V. M; CÂNDIDO, GA. Contemporaneidade do consumo sustentável e as suas correlações com as práticas empresariais e o comportamento do consumidor. In: ENCONTRO NACIONAL DA ASSOCIAÇÃO NACIONAL DE PÓS-GRADUAÇÃO E PESQUISA EM AMBIENTE E SOCIEDADE, 5, 2010, Florianópolis. Anais, 2010.

PALOMINO, E. A moda. São Paulo: Publifolha. (Folha Explica), 2003.

PINHEIRO, R. $M$ et al. Comportamento do consumidor e pesquisa de marketing. Rio de Janeiro: FGV, 2004.

SALCEDO, E. Moda ética para um futuro sustentável. São Paulo: Editora G. Gili, 2014.

SOLOMON, M. O comportamento do consumidor: comprando, possuindo e sendo. 5. ed. Tradução Lene Belon Ribeiro. Porto Alegre: Bookman, 2002. 